\title{
The effect of performing corrections on reported uterine cancer mortality data in the city of São Paulo
}

J.L.F. Antunes ${ }^{1}$ and $\mathrm{V}$. Wünsch-Filho ${ }^{2}$
${ }^{1}$ Departamento de Odontologia Social, Faculdade de Odontologia, ${ }^{2}$ Departamento de Epidemiologia, Faculdade de Saúde Pública, Universidade de São Paulo, São Paulo, SP, Brasil

\author{
Correspondence \\ J.L.F. Antunes \\ Departamento de Odontologia Social \\ Faculdade de Odontologia, USP \\ Av. Prof. Lineu Prestes, 2227 \\ 05508-900 São Paulo, SP \\ Brasil \\ Fax: +55-11-3091-7874 \\ E-mail: leopoldo@usp.br \\ Research supported by CNPq \\ (No. 302541/2004-7) and FAPESP \\ (No. 2003/09390-4).
}

Received September 15, 2005

Accepted April 5, 2006

\begin{abstract}
Reports of uterine cancer deaths that do not specify the subsite of the tumor threaten the quality of the epidemiologic appraisal of corpus and cervix uteri cancer mortality. The present study assessed the impact of correcting the estimated corpus and cervix uteri cancer mortality in the city of São Paulo, Brazil. The epidemiologic assessment of death rates comprised the estimation of magnitudes, trends (1980-2003), and area-level distribution based on three strategies: i) using uncorrected death certificate information; ii) correcting estimates of corpus and cervix uteri mortality by fully reallocating unspecified deaths to either one of these categories, and iii) partially correcting specified estimates by maintaining as unspecified a fraction of deaths certified as due to cancer of "uterus not otherwise specified". The proportion of uterine cancer deaths without subsite specification decreased from $42.9 \%$ in 1984 to $20.8 \%$ in 2003. Partial and full corrections resulted in considerable increases of cervix (31.3 and $48.8 \%$, respectively) and corpus uteri (34.4 and $55.2 \%$ ) cancer mortality. Partial correction did not change trends for subsite-specific uterine cancer mortality, whereas full correction did, thus representing an early indication of decrease for cervical neoplasms and stability for tumors of the corpus uteri in this population. Ecologic correlations between mortality and socioeconomic indices were unchanged for both strategies of correcting estimates. Reallocating unspecified uterine cancer mortality in contexts with a high proportion of these deaths has a considerable impact on the epidemiologic profile of mortality and provides more reliable estimates of cervix and corpus uteri cancer death rates and trends.
\end{abstract}

\section{Introduction}

Different histological, etiologic and epidemiologic features of uterine cancer require the anatomic specification of the tumor, which can originate in the corpus or in the cervix uteri. Erroneous estimates of mor-
Key words

- Uterine cancer

- Cervical cancer

- Mortality

- Statistical models

- Socioeconomic factors

- São Paulo tality rates are a long-standing concern affecting the epidemiologic assessment of uterine cancer in areas presenting a high percentage of uterine cancer deaths which are not specified as to the subsite where the tumor originated (1).

In its most prevalent form, corpus uteri 
cancer occurs in the surface mucous lining (endometrium) and is represented by adenocarcinomas; the same designation includes other histological types, such as sarcomas affecting the uterine muscle (myometrium). The risk of endometrial cancer has been reported to be associated with obesity, nulliparity and late menopause (2), and with hormone replacement therapy (3). Cervix uteri tumors are mainly of squamous cell histological type, a category of carcinomas whose etiology is considered to be one of the best known $(4,5)$, and a smaller proportion of cervical neoplasms refers to adenocarcinomas, with etiologic features analogous to those of corpus uteri cancer. Death certificates commonly classify as cancer of uterus NOS (not otherwise specified) cases lacking the identification of the subsite of the tumor. The topographic misclassification of cancer of the uterus indicates insufficient training of physicians filling out death certificates (6), in addition to possibly reflecting the high probability of delayed diagnosis and insufficient or inadequate medical assistance.

Percy et al. (7) attributed the decrease of mortality due to cancer of uterus NOS in the US to improved accuracy of health information. After comparing death certificates to hospital-based information, they proposed that a high proportion of these deaths should be recoded as cancer of the corpus uteri. In a survey of UK information, Swerdlow (8) observed that misspecification would not affect trends of cervical cancer mortality for women aged less than 50 years, because the reduced proportion of uterine cancer of unspecified location in this segment was compatible with the hypothesis of the majority of these cases being attributable to corpus uteri cancer.

Despite these observations, the appraisal of countries and age groups with a high proportion of deaths by misclassified uterine cancer suggests that attributing NOS deaths to corpus uteri cancer is not recommended because it hinders comparisons in time and geography of the epidemiologic profile of corpus and cervix uteri cancer deaths. Sanchez Garrido et al. (9) compared death certificates with medical information gathered by the Cancer Registry of Girona (Catalonia, Spain), and reported that only $20 \%$ of deaths formerly identified as uterus NOS should remain in this category. Of the remaining deaths, $24 \%$ were previously reported as incident cases of cervical cancer, $29 \%$ as corpus uteri cancer, $13 \%$ as cancer of the ovary, and $14 \%$ as cancer affecting other sites of the female reproductive system.

However, reviewing hospital records or cancer registries to supplement mortality information is hardly feasible. The perception of a large variation in the accuracy of death certificates within Europe led several studies (10-12) to propose the reclassification of deaths recorded as cancer of the uterus NOS. This correction consists of adjusting the number of deaths certified as corpus or cervix uteri cancer, by reallocating those previously classified as unspecified to either one of these two categories, according to the age-specific proportion of deaths specified in each country. This strategy was thought to be effective to reduce the problem of misclassification of uterine cancer and to allow inter-country comparisons of magnitude and trends of corpus and cervix uteri mortality.

The current study assessed two schemes for correcting estimates of unspecified uterine cancer deaths in a context previously reported as presenting an elevated proportion of these deaths: the city of São Paulo, Brazil (13). The objective of this study was to quantify the impact of corrections on the epidemiologic profile (i.e., the magnitude, temporal trends and area-level distribution) of data related to corpus and cervix uteri cancer.

\section{Material and Methods}

Official data on deaths occurring in the city of São Paulo from 1980 to 2003 were 
obtained from the system for information on mortality in the State of São Paulo, a database considered to be reliable by several studies (14-16). Mortality information was stratified by underlying cause, age, year, and area of residence. The stratification of underlying cause used the International Classification of Diseases, 9th revision (ICD-9), from 1980 to 1995 , and the 10th revision (ICD-10) from 1996 to 2003. Cervical cancer refers to the C53 ICD-10 code and 180 ICD-9 code; corpus uteri cancer refers to C54 (ICD-10) and 182 (ICD-9), and uterus NOS cancer refers to C55 (ICD-10) and 179 (ICD-9).

General censuses performed in 1980, 1991, 1996, and 2000 provided population information for the estimation of death rates. Time series analysis used yearly death rates calculated for the city of São Paulo from 1980 to 2003. The ecological assessment used average yearly death rates for each district of the city for the period 1995-2003 as a whole. Both analyses comprised the adjustment of death rates for the distribution of age groups by the direct method (17). The population of the city as a whole in 2003 was used as the standard population for this objective.

The current geographic division of the city into 96 districts was established in 1991 by governmental institutions for administrative purposes, in order to delimit regions with homogeneous socioeconomic status. The characterization of the city's districts used data provided by the census performed in 2000, which is the most recent source of population information. Literacy rate refers to persons aged 20 or more years. Years of study (averages) and high-school graduates (proportions) refer to the head of the household in each area. Income was measured in terms of household per capita average for each area. The Gini coefficient (18) was used to gauge inequality of income distribution at the area level. Population crowding (the number of dwellers per household) and the proportion of slum households (shantytowns) were used to characterize living standards in each area. The human development index is a composite measurement assembling information on income, instructional levels and longevity. The local health authority estimated this index for the city's districts according to methodological criteria set forth by the United Nations Development Programme (19).

Uterine cancer mortality was stratified by subsite for time series and ecological correlations. Three strategies were used to deal with the problem posed by unspecified uterine cancer deaths. The first one consisted in estimating mortality by solely using certified information on uterine cancer deaths. The second strategy, named "full correction", comprised the reallocation of deaths certified as cancer of uterus NOS to either corpus or cervix uteri according with the proportion of deaths originally certified for each category of cause, by year and age group (for time-series analysis), and by district of residence and age group (for the arealevel assessment). The third strategy, named "partial correction", performed the same calculation, though including a third category for "uterus NOS, corrected", considering that a parcel of deaths certified as due to unspecified uterine cancer in reality could not be specified, and should rather remain classified in this category.

These three strategies were used to estimate magnitudes, trends and ecological correlations (i.e., the assessment of association between death rates and indices of socioeconomic status at the area level) of mortality, and permitted the appraisal of the differential impact of corrections on the epidemiologic profile of subsite-specific uterine cancer mortality.

The magnitude of death rates was assessed as averages for the former (19801982) and the latter (2001-2003) periods. The estimation of trends used the PraisWinsten procedure of autoregression for 
time-series analysis (20). The association between district-level figures of uterine cancer mortality and co-variates of socioeconomic status used a nonparametric (Spearman's rho) correlation coefficient (17).

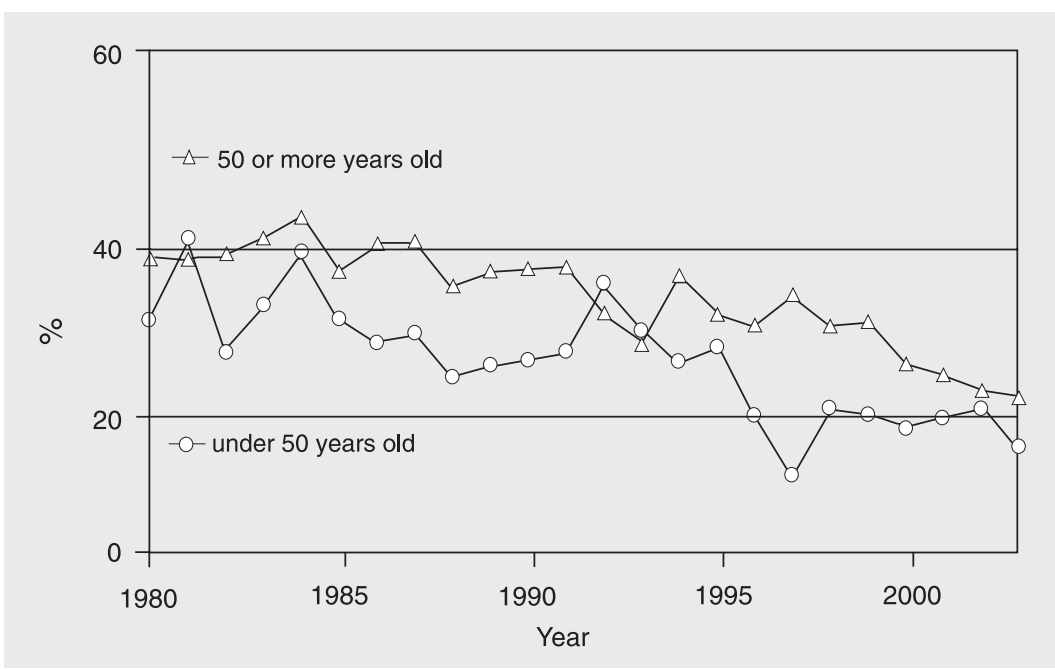

Figure 1. Uterine cancer deaths without specification of subsite in São Paulo, Brazil, 19802003. Data are reported as percent of total certified cervical cancer death.

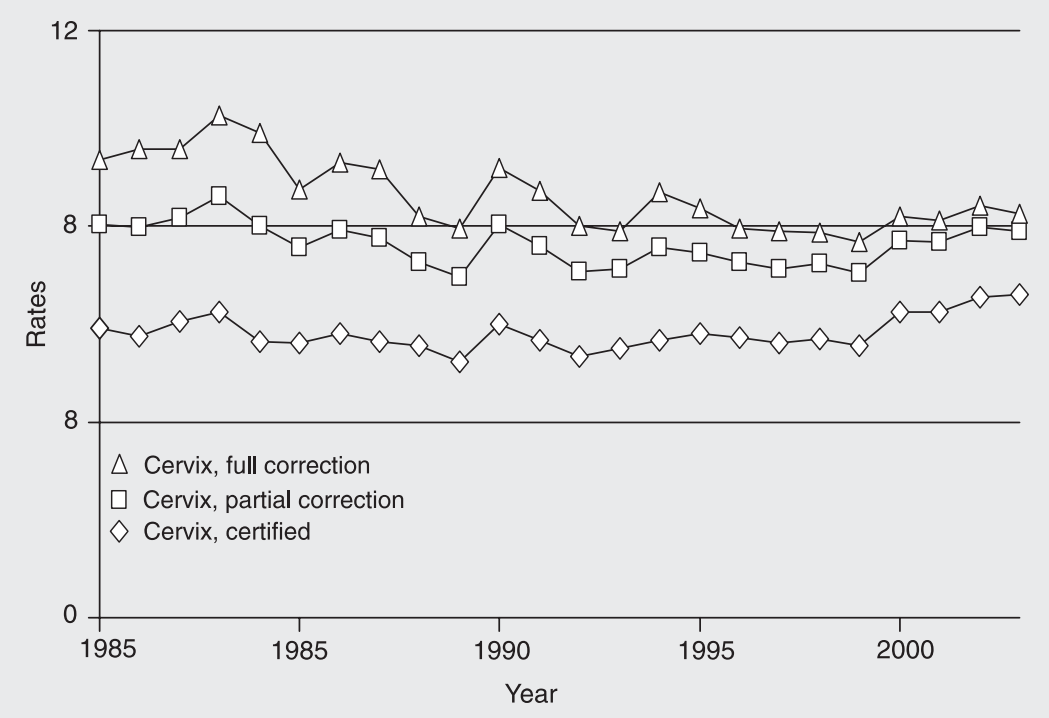

Figure 2. Cervical cancer mortality rates in São Paulo, Brazil, 1980-2003, corrected or not for NOS (not otherwise specified). Data are reported as frequency per 100,000 women with NOS on death certificate (certified), partially corrected to eliminate NOS (partial) of fully corrected.

\section{Results}

The proportion of uterine cancer deaths without specification of subsite presented a decreasing trend, though figures were relatively high during the entire study period (Figure 1). The overall proportion of unspecified uterine cancer was highest $(42.9 \%)$ in 1984 and lowest $(20.8 \%)$ in 2003. For women aged 50 or more years, deaths by uterus NOS cancer remained stationary at $40 \%$ during the 1980 's, progressively decreasing thereafter. Younger women presented lower percentages of uterus NOS cancer mainly during more recent years.

Time-series analysis for cervical cancer mortality indicated a stationary trend at nearly 6 deaths per year for each 100,000 women in the city (Figure 2, Table 1). Both the partial and the full correction resulted in a significant increase in the magnitude of cervical cancer mortality: the partial correction indicated a stationary $31.3 \%$ higher trend (nearly 8 deaths per 100,000 women), and the full correction indicated a decreasing trend at a rate of $8.62 \%$ per year, though maintaining, on average, a $48.8 \%$ higher magnitude (nearly 9 deaths per 100,000 women).

Corrections also resulted in modification of trends and increase of magnitude for corpus uteri cancer (Figure 3, Table 1). The rate of yearly increase observed for certified estimates of corpus uteri cancer mortality (9.53\%o per year) was attenuated after the partial correction $(4.16 \%$ oer year), while the full correction resulted in figure nonsignificantly different from zero, which indicates a stationary trend. Magnitude increased, on average, by 34.4 and $55.2 \%$, respective$1 y$, for the partial and the full correction during the study period.

Correction schemes did not present remarkable changes in the area-level distribution of either corpus or cervix uteri cancer mortality. Independently of considering certified estimates, either the partial or the full 
correction, analogous evidence is available for ecological correlations involving subsitespecific uterine cancer deaths (Table 2).

District-level figures of cervical cancer mortality correlated positively with illiteracy rate, Gini coefficient, proportion of households in shantytowns and crowding, and negatively with years of study, proportion of households' heads who were high-school graduates, income, and the human development index. These associations presented high-Spearman correlation coefficients and low $\mathrm{P}$ values, independent of being assessed for certified estimates or for the partial or the full correction. Cervical cancer death rates tended to rank higher in deprived areas of the city, thus presenting a negative socio- economic gradient, and this observation remained unchanged even after correcting mortality estimates (Table 2).

Noteworthy, mortality by corpus uteri cancer also indicated analogous ecological correlations for the three approaches, with death rates presenting consistent indications of a positive socioeconomic gradient. In contrast to cervix uteri cancer, corpus uteri cancer took its greatest toll in the most affluent areas of the city. As to ecological correlations involving uterus NOS mortality, certified estimates presented a negative socioeconomic gradient, while the partial correction resulted in a pattern of absent correlation with area-level indices of socioeconomic status (Table 2).

Table 1. Magnitude and trends of uterine cancer mortality in São Paulo, Brazil, 1980-2003.

\begin{tabular}{|c|c|c|c|c|c|c|c|c|}
\hline \multirow{2}{*}{$\begin{array}{l}\text { Magnitude and trends } \\
\text { (uterine cancer mortality) }\end{array}$} & \multicolumn{3}{|c|}{ Certified estimates } & \multicolumn{3}{|c|}{ Partial correction } & \multicolumn{2}{|c|}{ Full correction } \\
\hline & $\begin{array}{c}\text { Cervix } \\
\text { uteri }\end{array}$ & $\begin{array}{c}\text { Corpus } \\
\text { uteri }\end{array}$ & $\begin{array}{l}\text { Uterus, } \\
\text { NOS }\end{array}$ & $\begin{array}{c}\text { Cervix } \\
\text { uteri }\end{array}$ & $\begin{array}{c}\text { Corpus } \\
\text { uteri }\end{array}$ & $\begin{array}{l}\text { Uterus, } \\
\text { NOS }\end{array}$ & $\begin{array}{c}\text { Cervix } \\
\text { uteri }\end{array}$ & $\begin{array}{c}\text { Corpus } \\
\text { uteri }\end{array}$ \\
\hline Death rate (average 1980-1982) & 5.91 & 1.58 & 4.62 & 8.07 & 2.18 & 1.86 & 9.51 & 2.58 \\
\hline Death rate (average 2001-2003) & 6.47 & 2.18 & 2.50 & 7.86 & 2.71 & 0.59 & 8.27 & 2.88 \\
\hline Rate of yearly increase (\%) & +3.11 & +16.16 & -30.14 & -2.89 & +10.65 & -52.55 & -8.62 & +4.99 \\
\hline $95 \%$ confidence interval (\%०) & $-2.31 ;+8.55$ & $+9.53 ;+22.82$ & $-36.20 ;-24.03$ & $-7.49 ;+1.72$ & $+4.16 ;+17.19$ & $-65.13 ;-39.80$ & $-13.00 ;-4.22$ & $-1.60 ;+11.63$ \\
\hline Interpretation & Stationary & Increase & Decrease & Stationary & Increase & Decrease & Decrease & Stationary \\
\hline
\end{tabular}

NOS $=$ not otherwise specified

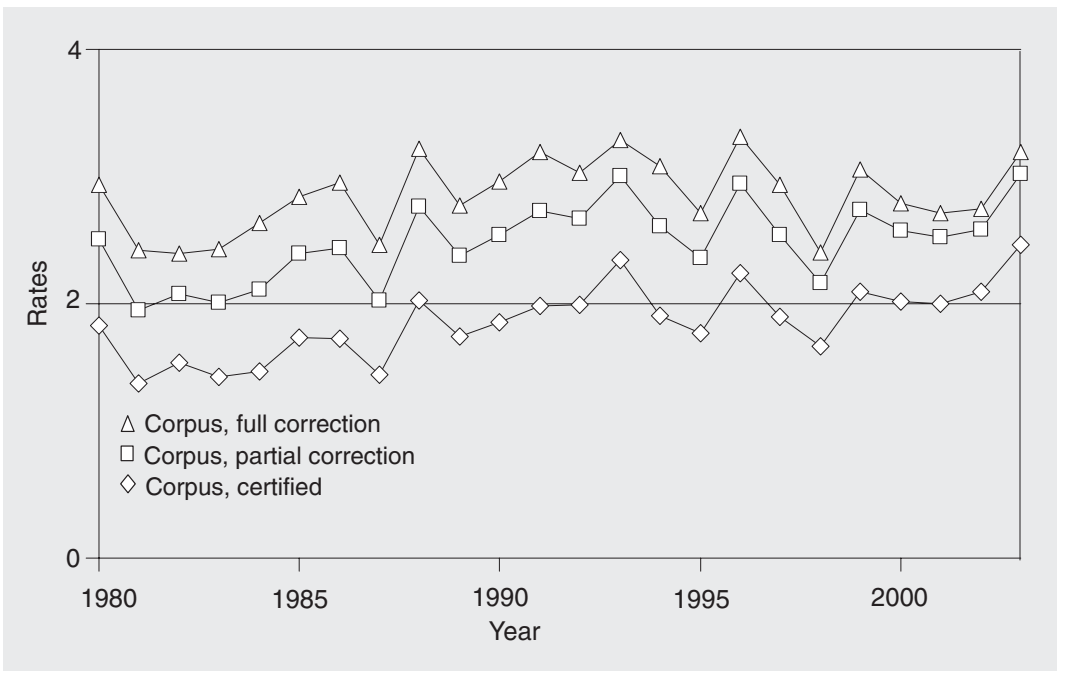

Figure 3. Corpus uteri cancer mortality rates in São Paulo, Brazil, 1980-2003, corrected or not for NOS (not otherwise specified). Data are reported as frequency per 100,000 women with NOS on death certificate (certified), partially corrected to eliminate NOS (partial) of fully corrected. 
Table 2. Goodness-of-fit assessment (Spearman correlation coefficient and $\mathrm{P}$ values) of the area-level association between socioeconomic indices and categories of uterine cancer mortality in São Paulo, Brazil, 1995-2003.

\begin{tabular}{|c|c|c|c|c|c|c|c|c|}
\hline \multirow[t]{3}{*}{ Socieconomic indices } & \multicolumn{8}{|c|}{ Correlation coefficient ( $P$ value) } \\
\hline & \multicolumn{3}{|c|}{ Certified estimates } & \multicolumn{3}{|c|}{ Partial correction } & \multicolumn{2}{|c|}{ Full correction } \\
\hline & $\begin{array}{c}\text { Cervix } \\
\text { uteri }\end{array}$ & $\begin{array}{c}\text { Corpus } \\
\text { uteri }\end{array}$ & $\begin{array}{l}\text { Uterus, } \\
\text { NOS }\end{array}$ & $\begin{array}{l}\text { Cervix } \\
\text { uteri }\end{array}$ & $\begin{array}{c}\text { Corpus } \\
\text { uteri }\end{array}$ & $\begin{array}{l}\text { Uterus, } \\
\text { NOS }\end{array}$ & $\begin{array}{l}\text { Cervix } \\
\text { uteri }\end{array}$ & $\begin{array}{c}\text { Corpus } \\
\text { uteri }\end{array}$ \\
\hline Illiteracy rate & $\begin{array}{l}+0.705 \\
(<0.001)\end{array}$ & $\begin{array}{c}-0.424 \\
(<0.001)\end{array}$ & $\begin{array}{c}+0.285 \\
(0.005)\end{array}$ & $\begin{array}{l}+0.682 \\
(<0.001)\end{array}$ & $\begin{array}{c}-0.445 \\
(<0.001)\end{array}$ & $\begin{array}{c}+0.071 \\
(0.490)\end{array}$ & $\begin{array}{l}+0.659 \\
(<0.001)\end{array}$ & $\begin{array}{c}-0.474 \\
(<0.001)\end{array}$ \\
\hline Years of study & $\begin{array}{c}-0.705 \\
(<0.001)\end{array}$ & $\begin{array}{l}+0.480 \\
(<0.001)\end{array}$ & $\begin{array}{c}-0.335 \\
(<0.001)\end{array}$ & $\begin{array}{c}-0.704 \\
(<0.001)\end{array}$ & $\begin{array}{l}+0.487 \\
(<0.001)\end{array}$ & $\begin{array}{l}-0.073 \\
(0.477)\end{array}$ & $\begin{array}{c}-0.686 \\
(<0.001)\end{array}$ & $\begin{array}{l}+0.510 \\
(<0.001)\end{array}$ \\
\hline$\%$ of high-school graduates & $\begin{array}{c}-0.700 \\
(<0.001)\end{array}$ & $\begin{array}{c}+0.488 \\
(<0.001)\end{array}$ & $\begin{array}{c}-0.340 \\
(<0.001)\end{array}$ & $\begin{array}{c}-0.700 \\
(<0.001)\end{array}$ & $\begin{array}{c}+0.493 \\
(<0.001)\end{array}$ & $\begin{array}{l}-0.080 \\
(0.441)\end{array}$ & $\begin{array}{c}-0.682 \\
(<0.001)\end{array}$ & $\begin{array}{c}+0.515 \\
(<0.001)\end{array}$ \\
\hline Income & $\begin{array}{c}-0.695 \\
(<0.001)\end{array}$ & $\begin{array}{l}+0.480 \\
(<0.001)\end{array}$ & $\begin{array}{c}-0.340 \\
(<0.001)\end{array}$ & $\begin{array}{c}-0.700 \\
(<0.001)\end{array}$ & $\begin{array}{l}+0.489 \\
(<0.001)\end{array}$ & $\begin{array}{l}-0.080 \\
(0.438)\end{array}$ & $\begin{array}{c}-0.684 \\
(<0.001)\end{array}$ & $\begin{array}{l}+0.516 \\
(<0.001)\end{array}$ \\
\hline Gini coefficient & $\begin{array}{c}+0.316 \\
(0.002)\end{array}$ & $\begin{array}{l}-0.081 \\
(0.433)\end{array}$ & $\begin{array}{c}+0.120 \\
(0.244)\end{array}$ & $\begin{array}{c}+0.292 \\
(0.004)\end{array}$ & $\begin{array}{l}-0.074 \\
(0.473)\end{array}$ & $\begin{array}{c}+0.003 \\
(0.980)\end{array}$ & $\begin{array}{c}+0.277 \\
(0.006)\end{array}$ & $\begin{array}{l}-0.084 \\
(0.416)\end{array}$ \\
\hline$\%$ of slum households & $\begin{array}{c}+0.459 \\
(<0.001)\end{array}$ & $\begin{array}{l}-0.107 \\
(0.298)\end{array}$ & $\begin{array}{r}+0.096 \\
(0.354)\end{array}$ & $\begin{array}{l}+0.446 \\
(<0.001)\end{array}$ & $\begin{array}{l}-0.131 \\
(0.202)\end{array}$ & $\begin{array}{l}-0.077 \\
(0.458)\end{array}$ & $\begin{array}{c}+0.436 \\
(<0.001)\end{array}$ & $\begin{array}{l}-0.169 \\
(0.100)\end{array}$ \\
\hline Household crowding & $\begin{array}{c}+0.678 \\
(<0.001)\end{array}$ & $\begin{array}{c}-0.460 \\
(<0.001)\end{array}$ & $\begin{array}{c}+0.352 \\
(<0.001)\end{array}$ & $\begin{array}{c}+0.680 \\
(<0.001)\end{array}$ & $\begin{array}{c}-0.470 \\
(<0.001)\end{array}$ & $\begin{array}{c}+0.096 \\
(0.355)\end{array}$ & $\begin{array}{l}+0.664 \\
(<0.001)\end{array}$ & $\begin{array}{c}-0.495 \\
(<0.001)\end{array}$ \\
\hline Human development index & $\begin{array}{c}-0.712 \\
(<0.001)\end{array}$ & $\begin{array}{c}+0.460 \\
(<0.001)\end{array}$ & $\begin{array}{l}-0.283 \\
(0.005)\end{array}$ & $\begin{array}{c}-0.708 \\
(<0.001)\end{array}$ & $\begin{array}{c}+0.469 \\
(<0.001)\end{array}$ & $\begin{array}{l}-0.023 \\
(0.827)\end{array}$ & $\begin{array}{c}-0.689 \\
(<0.001)\end{array}$ & $\begin{array}{l}+0.490 \\
(<0.001)\end{array}$ \\
\hline
\end{tabular}

NOS $=$ not otherwise specified .

\section{Discussion}

There is a long-standing concern regarding the specification of death causes for the elderly. Under conditions of material deprivation and reduced provision of diagnostic resources, the underlying cause of death would not be extensively investigated in the elderly, which would affect cancer statistics (21) and the general mortality (22). The current study indicated that, in the city of São Paulo, even for women aged less than 50 years, a non-negligible proportion (near $20 \%$ ) of uterine cancer deaths remained unspecified as to subsite during the most recent years. This observation reinforces the need of correcting estimates of corpus and cervix uteri cancer mortality in epidemiologic appraisals, because the exclusive use of certified information would produce unreliable estimates for both of these cancer types.

Loos et al. (23) stated the importance of reallocating unspecified uterine cancer deaths to estimate the most probable true rates of cervix and corpus uteri cancer. Geographic and temporal assessments would require such procedures in order to fulfill valid analyses. Based upon data related to eight European countries, they concluded that, without corrections, international comparisons of mortality from cancers of the cervix and corpus uteri, as well as studies of trends within and between countries, could lead to seriously misleading statistics. They also stated that this procedure should rather be performed based upon previously certified information than on surrogating proportions of a reference population, which would imply an additional source of variation for the estimates.

In the analysis of our data, we noted that death rates related to registered information on cancer of the uterus NOS had similar ecological correlations of cervical cancer mortality, and presented a negative socioeconomic gradient. This observation suggests that part of these deaths should indeed 
be reallocated to cervical cancer.

The perception that non-corrected death rates would involve underestimation of cervical cancer mortality is consistent with the study of Fonseca et al. (13), which appraised this category of cancer mortality as not specifically high in São Paulo, in the context of international comparisons. Early signs of the decline of cervical cancer mortality in Latin American countries (24) and in the Brazilian context (25) had already been reported to be masked by the misspecification of uterine cancer deaths, and the current study may provide quantitative evidence of this decrease. However, the assessment of a significant decreasing trend of cervical cancer mortality demanded a full reallocation of deaths by unspecified uterine cancer, and a further estimating process involves a higher risk of error. Therefore, additional studies should explore whether the decreasing trend of cervical cancer mortality is a statistical artefact or can effectively be stated for the city of São Paulo.

The World Health Organization recognizes cervical cancer as a major but solvable health problem among women in developing countries, by the implementation of health education, availability of standardized treatments, and effective early detection and referral policies (26). Although these resources are considered available for the Latin-American context (27), this category ranks only lower than skin and breast regarding cancer incidence in females, and only lower than breast, colon, lung, and stomach regarding cancer mortality in the city during recent years (28).

Robles et al. (29) attributed the persistence of stationary trends for cervical cancer mortality in the Americas as due to the implementation of cytological screening associated with prenatal and family planning programs, thus mostly serving younger women, while the real need is for screening the older ones, who are at a substantially higher risk. Lazcano-Ponce et al. (30) identified a high proportion of false-negative results and of specimens lacking endocervical cells, besides deficient knowledge of women as to the purpose of Pap smears, as additional factors for the low effectiveness of screening procedures in a Latin-American context. Studies performed in the city of São Paulo reported a lower coverage of cervical screening for women with poor socioeconomic status (and consequently at greater risk of cervical cancer), and identified the main hindrances to having a Pap smear: embarrassment, fear, difficulties in accessing health services, low schooling, and lack of motivation $(31,32)$.

The incidence of cervical cancer involves relevant behavioral risk factors (5) and its mortality is influenced by differential levels of access to and effectiveness of health services. These conditions would explain the negative socioeconomic gradient of the disease, which was not dependent on corrections regarding unspecified uterine cancer deaths. Cervical cancer presented unmistakable indications of association with deprivation in the city, a condition that had already been assessed at the ecological level in Spain (33) and in the Netherlands (34). Its trend was considered stationary by two out of three scenarios drawn in this study, and the correction schemes suggested major increases of magnitude. These observations indicate how much remains to be done for the control of the disease in the city of São Paulo.

Unlike most diseases, the incidence of corpus uteri cancer is higher for the upper social classes (35). However, this cancer form is treatable by surgical resection, and is considered to have a good prognosis. This observation would explain the report of higher mortality in the lower social classes (36-39), since these segments are less prone to a prompt detection and overall effective treatment. Nevertheless, the significant positive socioeconomic gradient of mortality by corpus uteri cancer in areas of the city sug- 
gests that medical care has not been effective in modifying the area-level distribution of incidence in São Paulo.

This consideration is aggravated by the observation that neither scheme for correcting the certified mortality by corpus uteri cancer modified its positive socioeconomic gradient. The concern regarding the effectiveness of medical care for patients with corpus uteri cancer is even more aggravated by the current indication that death rates are on the increase or, at least, have not decreased during the last twenty years. Furthermore, the elevated proportion of unspecified uterine cancer deaths indicates that, as well as for cervical cancer, figures of corpus uteri cancer mortality were rather underestimated in magnitude.

Several studies have reported relevant proportions of unspecified uterine cancer deaths or addressed the need of correcting estimates for cervical and corpus uteri cancer $(6-13,23-29,39,40)$. The current assessment of different strategies to perform this correction indicated important modifications of the epidemiologic profile of cervix and corpus uteri cancer. Besides resulting in remarkably higher magnitude of mortality, corrections indicated that trends of uterine cancer deaths may have been affected by subsite misspecification.

In conclusion, both the partial and the full corrections are preferable to exclusively appraising uncorrected information on uterine cancer mortality, an option that leads to an important underestimation of death rates for cervix and corpus uteri cancer. The partial correction represents a conservative option which considers that at least some of the deaths formerly classified as uterus NOS should remain unspecified as to the affected tissue. Although a further estimating process is subject to a higher risk of error, the full correction has been applied to several recent studies on uterine cancer mortality $(10,23,40)$.

In spite of the longstanding call for increased accuracy of the report of deaths by uterine cancer (7), the proportion of unspecified mortality remains high in the Brazilian context. Reallocating deaths certified as due to cancer of uterus NOS to either corpus or cervix uteri allows an improved epidemiologic assessment of subsite-specific uterine cancer mortality. Figures estimated by both strategies evaluated in the current study are deemed to be more reliable than those associated with the exclusive use of certified information. Therefore, they should be used preferably in epidemiologic assessments aimed at fostering health policies and programs that target reductions in the burden of disease and in unnecessary, avoidable and unfair inequalities in health.

\section{References}

1. Dunn JE Jr. Geographic considerations of endometrial cancer. Gynecol Oncol 1974; 2: 114-121.

2. Grady D, Erstner VL. Endometrial cancer. In: Schottenfeld D, Fraumeni JF Jr (Editors), Cancer epidemiology and prevention. 2nd edn. New York: Oxford University Press; 1996. p 1058-1089.

3. Fernandez E, Gallus S, Bosetti C, Franceschi S, Negri E, La Vecchia C. Hormone replacement therapy and cancer risk: a systematic analysis from a network of case-control studies. Int J Cancer 2003; 105: 408-412.

4. Schiffman MH, Brinton LA, Devesa SS, Fraumeni JF Jr. Cervical cancer. In: Schottenfeld D, Fraumeni JF Jr (Editors), Cancer epidemiology and prevention. 2nd edn. New York: Oxford University Press; 1996. p 1090-1116.

5. Franco EL, Duarte-Franco E, Ferenczy A. Cervical cancer: epidemi- ology, prevention and the role of human papillomavirus infection. CMAJ 2001; 164: 1017-1025.

6. Arbyn M, Geys H. Trend of cervical cancer mortality in Belgium (1954-1994): tentative solution for the certification problem of unspecified uterine cancer. Int J Cancer 2002; 102: 649-654.

7. Percy CL, Horm JW, Young JL Jr, Asire AJ. Uterine cancers of unspecified origin - a reassessment. Public Health Rep 1983; 98: 176-180.

8. Swerdlow AJ. Interpretation of England and Wales cancer mortality data: the effect of enquiries to certifiers for further information. $\mathrm{Br} \mathrm{J}$ Cancer 1989; 59: 787-791.

9. Sanchez Garrido MV, Izquierdo FA, Beltran FM, Bosch Jose FX, Viladiu QP. Trends in cervix cancer mortality in Catalonia, 19751992: analysis of death certificates and cancer registry of Girona. 
Gac Sanit 1996; 10: 67-72.

10. Bray F, Sankila R, Ferlay J, Parkin DM. Estimates of cancer incidence and mortality in Europe in 1995. Eur J Cancer 2002; 38: 99166.

11. Black RJ, Bray F, Ferlay J, Parkin DM. Cancer incidence and mortality in the European Union: cancer registry data and estimates of national incidence for 1990. Eur J Cancer 1997; 33: 1075-1107.

12. Jensen OM, Esteve J, Moller H, Renard H. Cancer in the European Community and its member states. Eur J Cancer 1990; 26: 11671256.

13. Fonseca LAM, Ramacciotti AS, Eluf Neto J. Tendência da mortalidade por câncer do útero no Município de São Paulo entre 1980 e 1999. Cad Saude Publica 2004; 20: 136-142.

14. Laurenti R, Mello-Jorge MHP, Gotlieb SLD. A confiabilidade dos dados de mortalidade e morbidade por doenças crônicas nãotransmissíveis. Ciênc Saúde Coletiva 2004; 9: 909-920.

15. Paes NA, Albuquerque ME. Evaluation of population data quality and coverage of registration of deaths for the Brazilian regions. Rev Saude Publica 1999; 33: 33-43.

16. Vasconcelos AMN. A qualidade das estatísticas de óbito no Brasil. Rev Bras Estud Popul 1998; 15: 115-124.

17. Daniel WW. Biostatistics: A foundation for analysis in the health sciences. New York: Wiley; 1995.

18. Creedy J. The dynamics of inequality and poverty: comparing income distributions. Cheltenham: E. Elgar; 1998.

19. United Nations Development Programme. Human development report 2001. Making new technologies work for human development. New York: Oxford University Press; 2001.

20. Johnston J. Econometric methods. New York: McGraw-Hill; 1991.

21. Doll R, Cook P. Summarizing indices for comparison of cancer incidence data. Int J Cancer 1967; 2: 269-279.

22. Lu TH, Shau WY, Shih TP, Lee MC, Chou MC, Lin CK. Factors associated with errors in death certificate completion. A national study in Taiwan. J Clin Epidemiol 2001; 54: 232-238.

23. Loos AH, Bray F, McCarron P, Weiderpass E, Hakama M, Parkin DM. Sheep and goats: separating cervix and corpus uteri from imprecisely coded uterine cancer deaths, for studies of geographical and temporal variations in mortality. Eur $J$ Cancer 2004; 40: 2794-2803.

24. Bosetti C, Malvezzi M, Chatenoud L, Negri E, Levi F, La Vecchia C. Trends in cancer mortality in the Americas, 1970-2000. Ann Oncol 2005; 16: 489-511.

25. Wünsch Filho $\mathrm{V}$, Moncau JE. Mortalidade por câncer no Brasil 1980-1995: padrões regionais e tendências temporais. Rev Assoc Med Bras 2002; 48: 250-257.
26. World Health Organization. Cervical cancer control in developing countries: memorandum from a WHO meeting. Bull World Health Organ 1996; 74: 345-351.

27. Arrossi S, Sankaranarayanan R, Parkin DM. Incidence and mortality of cervical cancer in Latin America. Salud Publica Mex 2003; 45 (Suppl 3): S306-S314.

28. Mirra AP, Latorre MRDO, Veneziano DB. Aspectos epidemiológicos do câncer no município de São Paulo: fatores de risco. São Paulo: Registro de Câncer; 2003.

29. Robles SC, White F, Peruga A. Trends in cervical cancer mortality in the Americas. Bull Pan Am Health Organ 1996; 30: 290-301.

30. Lazcano-Ponce EC, Buiatti E, Najera-Aguilar P, Alonso-de-Ruiz P, Hernandez-Avila M. Evaluation model of the Mexican national program for early cervical cancer detection and proposals for a new approach. Cancer Causes Control 1998; 9: 241-251.

31. Pinho AA, França Jr I, Schraiber LB, D'Oliveira AFPL. Cobertura e motivos para a realização ou não do teste de Papanicolaou no Município de São Paulo. Cad Saude Publica 2003; 19 (Suppl 2): S303-S313.

32. Brenna SMF, Hardy E, Zeferino LC, Namura I. Conhecimento, atitude e prática do exame de Papanicolaou em mulheres com câncer de colo uterino. Cad Saude Publica 2001; 17: 909-914.

33. Vioque J, Fenollar J. The distribution of cervical cancer mortality in Spain (1981-1986). An ecological study. Med Clin 1995; 104: 287292.

34. Kreuger FA, van Oers HA, Nijs HG. Cervical cancer screening: spatial associations of outcome and risk factors in Rotterdam. Public Health 1999; 113: 111-115.

35. Rimpela AH, Pukkala El. Cancers of affluence: positive social class gradient and rising incidence trend in some cancer forms. Soc Sci Med 1987; 24: 601-606.

36. Levi F, Negri E, La Vecchia C, Te VC. Socioeconomic groups and cancer risk at death in the Swiss Canton of Vaud. Int $J$ Epidemiol 1988; 17: 711-717.

37. Kogevinas M, Marmot MG, Fox AJ, Goldblatt PO. Socioeconomic differences in cancer survival. J Epidemiol Community Health 1991; 45: 216-219.

38. Kogevinas M, Porta M. Socioeconomic differences in cancer survival: a review of the evidence. IARC Sci Publ 1997; 177-206.

39. Zambon P, La Rosa F. Gynecological cancers: cervix, corpus uteri, ovary. Epidemiol Prev 2004; 28 (Suppl 2): 68-74.

40. Bray F, Loos AH, Oostindier M, Weiderpass E. Geographic and temporal variations in cancer of the corpus uteri: incidence and mortality in pre- and postmenopausal women in Europe. Int $J$ Cancer 2005; 117: 123-131. 